LENTERA PENDIDIKAN, EDISI X, NO. 2, DESEMBER 2007 (185-195)

\title{
AKTOR PEMBENTUK JARINGAN PESANTREN DI SULAWESI SELATAN 1928-1952
}

Oleh: Syamsuddin Arief

\begin{abstract}
Anre Gurutta Haji (A.G.H) Muhammad As'ad is one of the actors of forming Islamic Boarding Schools in South Sulawesi. He went back from Makkah and went to Sengkang-Wajo in 1928. He graduated from al-Falah Makkah Mukarramah. He studied to the great Ulamas in the Mesjidil Haram (Haram Mosque). Among of his teachers were Syekh Abdul Rasyid al-Bugis, Syekh Ambo Wellang alBugis, Syekh Abbas Abdul Jabbar al-Bugis, Syekh Mallawa al-Bugis, Syekh Umar Hamdani (the traditional expert), Syekh Ahmad Azdirin, Syekh Jamal Makki, Syekh al-Abrar, Syekh Muhammad Said alYamani, and Syekh Hasan al-Yamani. Another students of A.G.H Muhammad As'ad who helped as teachers such as A.G.H Abdurrahman Ambo Dalle, A.G.H Daud Ismail, A.G.H Yunus Maratn, Hamzah Badawi, Abdul Malik Muhammad, A.G.H Muhammad Abduh Pabbaja, Abdul Muin Yusuf, and Abdul Azis (North Luwu).
\end{abstract}

KEYWORDS: Aktor, jaringan, pesantren, kiai

TERLEPAS dari apakah historiografi Indonesia dibahas dalam konteks lokal atau global, yang jelas bahwa sejarah Islam di Indonesia tidak lagi hanya dilihat dari perspektif lokal, sebagaimana kecenderungan banyak sejarawan, tetapi kini mulai bergeser dengan melihat sejarah Islam dalam perspektif global, yakni melihat sejarah Islam di Indonesia dalam kaitan dengan perkembangan historis Islam di kawasan lain. ${ }^{1}$ Karya Azyumardi Azra - jika dipakai untuk melihat jaringan intelektual Nusantara abad ke17 dan ke-18 di Mekkah dan Madinah, termasuk respon dan tema-tema penting yang dikembangkan di Nusantara setelah kembali dari Timur Tengah dalam kaitannya dengan "jaringan ulama" - sangatlah berharga dalam tradisi keilmuan.

Lebih tegas lagi menurut Azra, perjalanan historis Islam di Indonesia sepanjang sejarah tidak bisa dilepaskan dari perkembangan Islam di kawasan Arab dan kawasan muslim lainnya. Oleh karena itu, kajian-kajian tentang Islam di Indonesia yang mengabaikan faktor ini diprediksi gagal memahami Islam di Nusantara secara akurat. ${ }^{2}$ Apa yang bisa dipahami dari "dinamika intelektual" ulama Nusantara di Timur Tengah adalah seperti 
yang disebut oleh Abaza sebagai "cultural change" (pertukaran budaya) atau "transmission of Islamic learning" (transmisi ilmu Islam).

Transmisi keilmuan Nusantara termasuk Sulawesi Selatan secara umum terkait dengan dinamika Islam pada tingkat global yakni pergolakan intelektual di Timur Tengah dengan ciri kosmopolitan. Dinamika intelektual di Timur Tengah khususnya Mekkah-Madinah turut mempengaruhi gelombang pasang-surut keilmuan di Nusantara pada tingkat lokal. Lebih jauh lagi, dinamika Islam tingkat lokal muncul dari sejauhmana respons ulama Nusantara terhadap perkembangan intelektual ulama di Mekkah-Madinah. ${ }^{3}$

Seiring dengan munculnya ide pembaruan Islam yang digagas oleh Muhammad ibn Abdul Wahab (1703-1798) di Arab Saudi, Syah Waliyullah al-Dihlawi (1703-1781) dan Sayyid Ahmad Khan (1817-1897), keduanya berasal dari Indo-Pakistan, Sayyid Jamaluddin al-Afgani (1837-1897) serta Muhammad Abduh (1849-1905), keduanya dari Mesir, memberikan warna dan pengaruh yang tidak kecil pada wacana keislaman abad 20. Pengaruh wacana pembaruan ini pada akhirnya menyentuh wilayah Nusantara yang kemudian mengkristal pada sejumlah organisasi pembaruan Islam di Indonesia yakni Jam'iyah Khair (1905), Syarekat Islam (1911), Persyarikatan Ulama (1911), Muhammadiyah pada 1912, serta Nahdatul Ulama (NU) 1926.4

Dari sisi mobilitas penduduk, dibukanya Terusan Suez pada 1869 mendorong muslim Nusantara secara massif untuk menunaikan ibadah haji di Mekkah dan berkunjung ke Madinah untuk keperluan menuntut ilmu. ${ }^{5}$ Gelombang hijrah santri Nusantara awal abad 19 sampai awal abad 20 kemudian melahirkan guru-guru utama (Ulama Jawi), baik yang berkiprah di pusat keilmuan Islam al-Haramain maupun yang kembali ke Nusantara menjadi kiai pesantren abad 19 dan 20. Ulama besar seperti Nawawi al-Bantani (1813-1897), Mahfuz at-Tirmisi atau Mahfuz Tremas (w. 1919), Khalil Bangkalan (1819-1925), R. Asnawi Kudus (1861-1959), serta Hasyim Asy'ari (1871-1947) adalah guru-guru intelektual tradisi pesantren Jawa-Madura. ${ }^{6}$ Masalah yang muncul kemudian adalah siapakah aktor jaringan pesantren di Sulawesi Selatan pada abad ke 20.

\section{PERKEMBANGAN PESANTREN DI SULAWESI SELATAN}

Muncul dan berkembangnya pendidikan Islam termasuk pesantren di Sulawesi Selatan terlepas dari wacana keagamaan di Haramain dan Nusantara abad 20. Dari preseden sejarah membuktikan bahwa pendidikan pesantren di Sulawesi Selatan secara tidak langsung dimulai sejak Islam diterima di Makassar pada 1605. Jasa besar tiga datuk dari Minangkabau 
sebagai utusan Kerajaan Aceh tidak bisa diabaikan. Lebih menarik lagi bahwa salah satu datuk yakni Datuk ri Bandang (Abdul Makmur Khatib Tunggal) adalah Murid Sunan Giri (w. 1530). ${ }^{7}$ Ulama Bugis-Makassar selanjutnya yang mengembangkan pendidikan Islam adalah Syekh Yusuf al-Makassar abad 17, Abdul Wahab al-Bugisi abad 18, serta beberapa nama seperti Abdul Basyir al-Dhahir al-Rappani (berasal dari Rappang Sidrap), Nur al-Din bin Abdul Fatah dan Abdul Qadir Karaeng Jeno. Belum ditemukan data yang memadai mengenai ulama Bugis-Makassar yang mewakili guru intelektual abad 19, kecuali bahwa resesi sosial-politik di Kerajaan Wajo pertengahan abad 19 memaksa migrasi besar-besaran orang Wajo ke beberapa wilayah di Nusantara dan Mekkah yang kemudian dihubungkan dengan dibukanya Terusan Suez tahun 1861. Pandangan ini cukup dapat menjelaskan keberadaan orang Bugis-Wajo di Mekkah abad 19 yang kemudian melahirkan sosok "arsitek pesantren" abad 20 di Sulawesi Selatan, meminjam istilah Abdurrahman Mas'ud, yakni alAllamah Syekh Muhammad As'ad yang lebih populer disebut "Gurutta As'ad atau Gurutta Sade."

Secara teknis, istilah pesantren di Sulawesi Selatan secara umum baru dikenal pada tahun 1970-an sejalan dengan penggunaan gelar kiai di kalangan komunitas santri pesantren. Awalnya, penamaan madrasah atau perguruan adalah istilah untuk menyebut lembaga pendidikan Islam awal abad 20 di Sulawesi Selatan. Oleh karena itu, sejak awal pembentukannya pada 1930, As'adiyah sudah menggunakan istilah madrasah untuk membedakannya dari sistem pendidikan yang lain kala itu seperti Sekolah Muhammadiyah, HIS, dan Sekolah Rakyat.

Terbentuknya tradisi pesantren berasal dari hubungan dan relasi intelektual (relasi pendidikan) yang melibatkan guru-murid (vertikal) dan dinamika yang berlangsung pada komunitas guru-guru dan murid-murid (horizontal). Relasi intelektual yang dibangun oleh arsitek pesantren Sulawesi Selatan abad 20, Gurutta As'ad diperoleh di Haramain, pusat intelektual dunia Islam. Bermula dari belajar al-Qur'an, Nahwu, dan Sharaf pada ayahnya, Syekh Abdul Rasyid. Meskipun belum ada informasi yang menyebutkan siapa gurunya Abdul Rasyid, tetapi besar kemungkinan Gurutta Abdul Rasyid berguru pada ulama Haramain akhir abad ke-19. Pada saat itu, ulama Jawi Syekh Nawawi al-Bantani (1813-1897) dan Syekh Ahmad Khatib al-Sambas (w. 1878) sudah menjadi guru utama bagi komunitas Jawi di Haramain. ${ }^{8}$ Bukan tidak mungkin kedua tokoh tersebut menjadi guru Abdul Rasyid al-Bugisi.

Gurutta As'ad memang terlahir dari keluarga ulama Bugis dari ayahnya (Abdul Rasyid) dan pamannya (Gurutta Ambo Wellang). Kendati 
demikian, yang membentuk jaringan kiai dan pesantren di Sulawesi Selatan abad 20 adalah relasi intelektual atau hubungan keilmuan antara guru-murid. Hal ini dibuktikan bahwa anak-anak gurutta As'ad lebih memilih jalur tahfiz al-Qur'an (menghafal al-Qur'an) dibanding menjadi guru-guru intelektual di pesantren. Meskipun sebahagian anak Gurutta As'ad mempunyai tingkat keilmuan yang tinggi, tetapi tampaknya mereka tidak memilih pesantren sebagai jalur artikulasi keilmuannya. Misalnya, Gurutta Abd Rasyid As'ad, memilih tawaran menjadi ulama MUI dan Imam Besar Masjid Agung Kab. Luwu. ${ }^{9}$

\section{Relasi Intelektual: Vertikal dan Horizontal}

Tampaknya Syekh Muhammad Said al-Yamani dan Syekh Umar Hamdani adalah guru utama yang mempertemukan relasi intelektual Gurutta As'ad (lahir 1907) dengan beberapa ulama Nusantara seperti Hasyim Asy'ari (lahir 1871), Anwar Musaddad Garut (lahir 1903), Zain Mun'im Probolinggo (lahir 1906), TG. Zainuddin Pancor Lombok (lahir 1908), Ali Maksum Rembang (lahir 1915),10 dan Habib Ali al-Habsyi, Kwitang Jakarta (1870-1968). Ulama yang disebut terakhir adalah guru utama ulama Betawi yang banyak melahirkan generasi ulama berikutnya. ${ }^{11}$

Jaringan intelektual Gurutta As'ad yang terbangun dari relasi gurumurid bisa dilacak pada pengembaraan keilmuannya mempelajari kitab klasik dari beberapa ulama Haramain seperti Syekh Umar Hamdani alMagribi, Syekh Abbas Abdul Jawad, Syekh Hasan al-Yamani, Syekh Said al-Yamani, Syekh Jamal al-Makki, Syekh Ahmad Nadzirin, dari Syekh Abrar. Di samping itu, tidak kalah pentingnya adalah ulama Bugis di Mekkah seperti Syekh Mallawa, Syekh Abdul Rasyid, Syekh Jamal alMakki, serta Syekh Ambo Wellang.

Ketika memulai pendidikan madrasah (MAI) sengkang tahun1930, Gurutta As'ad menjalin kerja sama yang baik dengan beberapa ulama kenamaan Timur Tengah. Beberapa nama bisa dicatat seperti Syekh Abdullah Dahlan (Mufti Mekkah), Syekh Mahmud al-Jawwad (Qadhi Medinah), Syekh Husein (Bone), Syekh Ahmad al-Afifi al-Misri (Mesir), serta Syekh Abdullah. Bahkan dua orang ulama ternama yakni Habib Salim bin Jindan (1906-1969), ahli Hadis, dan Prof. Hamka pernah berkunjung untuk bertukar pikiran mengenai suatu masalah dengan Gurutta As'ad. Hal ini menandakan bahwa keahlian dan keilmuan Gurutta As'ad telah dikenal luas bukan hanya terbatas pada komunitas Bugis-Makassar, tetapi juga pada ulama Nusantara. Relasi ini tidak saja menambah dinamika keilmuan pada tingkat santri, tetapi juga menjadi pembuk-tian bahwa mereka itu adalah penerjemah "Islam tradisi" dan perantara ilmu- 
ilmu klasik berupa fikih, hadis, tafsir, tasawuf, kalam, tauhid dan bahasa Arab pada komunitas santri Bugis-Makassar awal abad 20.

Pada sisi lain, relasi intelektual murid Gurutta As'ad dengan sejumlah murid lainnya melahirkan komitmen untuk mengembangkan pendidikan Islam tradisional (madrasah dan pesantren). Tidaklah berlebihan jika nama besar Gurutta As'ad al-Bugisi, pendiri As'adiyah (Sengkang) ${ }^{11}$ mampu menyedot dan mempengaruhi santri-santri awal yang kelak menjadi tokoh pesantren dan elit sosial-agama di Sulawesi Selatan abad 20 sampai sekarang. Pesantren inilah kemudian yang menjadi cikal-bakal lahirnya beberapa pesantren di Sulawesi Selatan. Ulama-ulama murid beliau antara lain Gurutta Abdurrahman Ambo Dalle (Darud Dakwah Wal Irsyad), Gurutta Daud Ismail (Yastrib-Beowe) di Soppeng, Gurutta Yunus Maratan (As'adiyah), Gurutta Abdul Malik, Gurutta Hamzah Badawi, Gurutta Hamzah Manguluang di Sengkang, Gurutta Abdul Kadir Khalid (Ma'had Dirasah al-Islamiyah wa al-'Arabiyah) di Makassar, Gurutta Abduh Pabbaja (al-Furqan) di Parepare, dan Gurutta Abdul Muin Yusuf (Pesantren al'Urwat al-Wutsqa) di Sidenreng Rappang, Gurutta Amberi Said (DDI Mangkoso), Gurutta Fasih Mustafa (DDI al-Ikhlas-Takkalasi Barru), Gurutta Marzuki Hasan (Dar al-Istiqamah Maros), Guruttta Muhammad Said (Pesantren Tahfiz 77) di Bone, Gurutta M. Sunusi Batjo (Nahdatul Ulum, Maros), Gurutta Abdul Azis (Nurul Junaidiyah Burau Luwu Utara), Gurutta Muhammad Marzuki Hasan (Darul Istiqamah) di Maccopa-Maros, Gurutta H. Syuaib Mas'ud (Babul Khaer) Bulukumba, serta pesantren lain.

Pada hakikatnya, perkembangan sebuah pesantren sangat bergantung pada kemampuan pribadi gurutta. Sosok gurutta, ${ }^{12}$ khususnya di Sulawesi Selatan, termasuk juga kiai di Jawa, Sumatra, Kalimantan, dan Madura, merupakan figur kunci bagi eksistensi pesantren (lembaga pendidikan). Transmisi keilmuan yang diusahakan oleh beberapa ulama awal khususnya pada awal abad ke-20 menjadi embrio terbentuknya lembaga pendidikan Islam (pesantren dan madrasah). Pengajian-pengajian dalam bentuk "mangngaji tudang"13 telah banyak dirintis ulama lokal di beberapa daerah di Sulawesi Selatan.

Jadi, proses terbentuknya jaringan dan kiai pesantren di Sulawesi Selatan abad 20 lebih kuat melalui relasi intelektual antara guru-murid, dan relasi horizontal sesama guru dan murid pengembaraan ilmu klasik; fikih, hadis, al-Qur'an, tauhid, kalam, mantiq serta ilmu bahasa Arab, sebagai yang terdapat dalam kitab kuning serta melalui transmisi ajaran sufistik (tasawuf). Adapun jaringan genealogis kiai-pesantren di Sulawesi Selatan tidak begitu tampak. Tidak seperti dalam kultur pesantren JawaMadura, hubungan kekerabatan sesama kiai tidaklah menjadi mainstream 
yang membentuk suatu poros jaringan pesantren. Mungkin sekali hal ini disebabkan oleh hampir semua pesantren di Sulawesi Selatan dibangun dan dibentuk oleh masyarakat muslim setempat.

\section{Aktor Pembentuk Jaringan Pesantren}

Aktor pembentuk jaringan pesantren di Sulawesi selatan adalah para ulama yang diberi gelar anre gurutta (maha guru kita), bersama dengan santri seniornya atau yang digelar dengan pembantu anre gurutta. Mereka inilah yang kelak di kemudian menjadi tokoh-tokoh pendiri dan pengembang pesantren di Sulawesi Selatan, bahkan di luar propinsi Sulawesi Selatan. Posisi sosial tampak dimana raja dan ulama sebagai aktor jaringan. Organisasi sebagai aktor jaringan pesantren adalah organisasi Muhammadiyah, Nahdatul Ulama, dan Syarikat Islam.

Salah satu aktor pembentuk jaringan pesantren mulai tahun 1928 sampai wafatnya 1952 adalah Anre Gurutta Syekh Muhammad As'ad alBugisi (1907-1952).

\section{Sejarah Hidup dan Wafatnya}

Gurutta Muhammad As'ad al-Bugisi14 atau lebih dikenal dengan Gurutta As'ad lahir pada tanggal 12 Rabi' al-Tsani 1326 H. (1907 M.). Ayahnya adalah seorang ulama Bugis yang bermukim di Mekkah bernama Syekh Abdul Rasyid al-Bugisi. Ibunya bernama al-Hajjah Sitti Salehah binti Abdurrahman Guru Teru al-Bugisy. Guruta As'ad adalah aktor jaringan pesantren di Sulawesi Selatan pada tahun 1928. Ia perintis pendidikan Islam dengan mengkombinasikan metode tradisional halaqah (mangngaji tudang) dengan sistem klasikal (madrasah) pada awal abad ke-20. Gurutta As'ad adalah salah seorang ulama yang besar peranannya dalam pengembangan pondok pesantren di Sulawesi Selatan. Semasa hidupnya, beliau mempersunting empat perempuan dengan sepuluh orang anak.

\section{Latar Belakang Pendidikan}

Gurutta Hamzah Mangguluang menyebutkan bahwa Gurutta As'ad telah menghafal al-Qur'an pada usia 14 tahun dan pada saat itu juga dipercaya menjadi Imam salat tarwih di Masjid al-Haram (Mekkah). ${ }^{15}$ Dasar pendidikan agama didapatkan langsung dari ayahnya di Mekkah.

Gurutta As'ad telah mampu menghafal beberapa matan kitab antara lain Sullam al-Manthiq, Manzhûmah Ibn Syahniah, dan al-Nuhbah al-Azhariyah yang dipelajari dari gurunya Syekh Ambo Wellang, seorang ulama bugis yang bermukim di Mekkah. ${ }^{16}$ Beliau pernah berguru pada tahun $1343 \mathrm{H}$. (1924 M.), kepada seorang ulama besar al-Allâmah al-Syekh Abbâs Abd al- 
Jabbâr17, dan pada tahun 1344 H. (1925 M.), Gurutta As'ad melanjutkan pelajarannya pada seorang ulama besar yaitu Syekh Mallawa (ulama Bugis). ${ }^{18}$ Pada usia 18 tahun, Gurutta As'ad memperdalam beberapa kitab dan juga memperoleh pengajaran dari Syekh Jamal al-Makkî. ${ }^{19}$

Sebelum menyempatkan diri belajar pada seorang ulama besar di Madinah, Gurutta As'ad masih sempat belajar pada seorang ulama besar, Syekh Abrâr untuk mendalami ilmu manthiq. ${ }^{20}$ Sebelum Gurutta pulang ke Indonesia (Sengkang-Wajo), beliau berguru langsung pada seorang ahli hadis, Syekh Ahmad Sanusi (Qadhi Medinah dan Pemimpin Tarekat Sanusiyah), dan sempat menjadi sekretaris pribadi gurunya selama beberapa waktu. ${ }^{21}$

Tampak bahwa latar belakang pendidikan Gurutta As'ad dan disiplin ilmunya sangat beragam sebab beliau belajar dari ulama-ulama besar pada zamannya. Gurutta As'ad belajar selama 7 tahun dan menamatkan pendidikan formalnya di Madrasah al-Falâh (Mekkah). Besar kemungkinan terjadi pengembaraannya pada beberapa varian lembaga pendidikan pesantren dan madrasah di Sulawesi Selatan pada tahun 1928-1952.

Pada tahun 1928, Gurutta As'ad kembali ke tanah leluhurnya di Sengkang-Wajo, dan melihat banyak praktek-praktek masyarakat yang menyimpang dari ajaran Islam. Beliau membuka pengajian tersendiri (1914-1928 M.) mulai dari halaqah sampai pendidikan formal di Madrasah al-Falah turut memberi andil dalam kiprahnya merintis dan mengembangkan di rumahnya sambil membantu pengajian kitab pamannya, Gurutta Ambo Emme. Jumlah santri yang ikut pengajian halaqah (mangaji tudang) semakin bertambah baik dari Sengkang dan sekitarnya maupun dari luar daerah. Oleh karena itu, pengajian dipindahkan ke Masjid Jami' Sengkang. Sejak Mei 1930, beliau membuka sistem pendidikan formal bentuk madrasah bertempat di samping Masjid Jami' Sengkang bernama Madrasah Arabiyah Islamiyah (MAI). ${ }^{22}$ Setelah dua tahun kemudian, atas bantuan pemerintah Kerajaan Wajo (Petta Ennengnge) dibangunlah gedung madrasah permanen yang bertempat di samping kiri-kanan Masjid Jami' Sengkang.

Lepasan MAI Sengkang umumnya mendirikan pesantren di berbagai daerah. Gurutta Ambo Dalle mendirikan MAI Mangkoso pada tahun 1937 kemudian berubah menjadi DDI Mangkoso pada tahun 1948. Gurutta Daud Ismail mendirikan Yastrib Soppeng, Gurutta Abduh Pabbaja mendirikan alFurqan Parepare, Gurutta Junaid Sulaiman mendirikan Ma'had Hadis Bone, Gurutta Muin Yusuf mendirikan Pesantren al-'Urwah al-Wutsqa, Gurutta Marzuki Hasan mendirikan Pesantren Dar al-Istiqamah di Maros dan Sinjai, dan lain-lain. 
Gurutta As'ad wafat pada Senin 12 Rabi'ul Awwal tahun 1372 H. (29 Desember 1952 M.). Sepeninggal Gurutta, MAI Sengkang dipimpin oleh murid beliau, Gurutta Daud Ismail yang terpilih dalam musyawarah pada 25 Sya'ban 1372 H. (9 Mei 1953 M.). Pada periode inilah warga MAI Sengkang mengadakan musyawarah dan sepakat untuk mengubah Madrasah Arabiyah Islamiyah (MAI) menjadi Madrasah As'adiyah (MA) Sengkang. ${ }^{23}$ Setelah perubahan nama menjadi Madrasah As'adiyah (MA) Sengkang, maka salah satu kebijkasanaan penting yang dilakukan yaitu membentuk dan membuka cabang-cabang madrasah di beberapa tempat di luar Sengkang sesuai permintaan masyarakat.

Hingga sekarang, Pesantren As'adiyah Sengkang telah dipimpin beberapa ulama yaitu Gurutta As'ad al-Bugisi (1930-1952), Gurutta Daud Ismail (1953-1961), Gurutta Muhammad Yunus Martan (1961-1986), Gurutta Hamzah Badawi (1986-1988), ${ }^{24}$ Gurutta Abdul Malik Muhammad (19882000), Gurutta Abdul Rahman Musa (2000-2003), dan sekarang Gurutta M. Rafi'i Yunus Martan (2003-2008). ${ }^{25}$

\section{PENUTUP}

Penulis hanya mengungkap satu tokoh sebagai sentral aktor jaringan pembentuk pesantren di Sulawesi Selatan pada abad 20, karena keterbatasan halaman, maka tidak memungkinkan menguraikan semua aktor pembentuk jaringan pesantren di Sulawesi Selatan. Adapun terbentuknya jaringan pesantren di Sulawesi Selatan ditandai dengan sangat eratnya hubungan penguasa atau raja dengan masyarakatnya yang menghendaki adanya pendidikan Islam di Daerah Sulawesi Selatan.

Bahwa untuk menciptakan kemajuan beragama dan mengisi masjid untuk salat berjemaah perlu dibangun komunitas pendidikan Islam yang menunjukkan adanya kerjasama antara semua kelompok sosial masyarakat dan tokoh-tokoh organsasi Islam seperti Muhammadiyah, NU, dan PSII beserta organisasi Islam lainnya.

\section{CATATAN AKHIR:}

1. Azyumardi Azra, Historiografi Islam Kontemporer: Wacana, Aktualitas, dan Ator Sejarah, Jakarta: PT. Gramedia Pustaka Utama, 2002, h. 9.

2. Azyumardi Azra, Historiografi Islam Kontemporer: Wacana, Aktualitas, dan Ator Sejarah, h. 9.

3. Mastuki dan M. Ishom el-Saha, Intelektualisme Pesantren: Potret Tokoh dan Pertumbuhan Pesantren, cetakan kedua, Jakarta: Diva Pustaka, 2004, h. 16.

4. Suwito dan Muhbib, "Jaringan Intelektual Kyai Pesantren di Jawa-Madura Abad 20", Laporan Penelitian, Jakarta: Depag RI, 2000, h. 50. Lihat juga A. Mukti 
Ali, "K.H. Ahmad Dahlan dalam Perspektif Kebangkitan Islam", dalam Endang Basri Ananda (ed.), 70 Tahun Prof. Dr. H.M. Rasyidi, Jakarta: Harian Pelita, 1985, h. 294-298.

5. Abdurrahman Mas'ud, Dari Haramain ke Nusantara: Jejak Intelektual Arsitek Pesantren, Jakarta: Kencana, 2006, h. 109-228.

6. Mastuki HS dan M. Ishom, Intelektualisme Pesantren: Potret Tokoh dan Cakrawala Pemikiran di Era Pertumbuhan Pesantren, Jakarta: Diva Pustaka, 2003, h. 14.

7. Syekh Nawawi menurut Hurgronje, seperti dikutip Abdurrahman Mas'ud, adalah seorang pengikut setia Syekh Ahmad Khatib Sambar, seorang pendiri tarekat Qadiriyah Naqsyabandiyah. Syekh Nawawi adalah seorang pengikut Sunni dan penganut sufisme al-Ghazali.

8. Luwu adalah sebuah kabupaten otonom. Dahulu, daerah ini pernah menjadi Kerajaan Islam terbesar abad 17 dan menjadi asal usul kerajaan Bugis berikutnya. Sekarang, kabupaten Luwu dipecah menjadi Kota Palopo, Kabupaten Luwu, Kabupaten Luwu Utara, dan Kabupaten Luwu Timur.

9. Lihat Muhammad Irfan Hasanuddin, "The Pesantren As'adiyah Sengkang: A Study on Continuity and Change of Pesantren Tradition", Thesis, Jakarta: UIN Syarif Hidayatullah Jakarta, 2006, figure 2.

10. Hasbi Indra, Pesantren dan Transformasi Sosial: Studi Atas Pemikiran K. H. Abdullah Syafei dalam Bidang Pendidikan Islam, Jakarta: Penamadani, 2003, h. 119. Dijelaskan bahwa pada umumnya ulama Betawi adalah murid Habib Ali alHabsyi Kwitang. Lahir pada 1870 dan wafat 1968 dalam usia 102 tahun. Pada tahun 1887, dia mendirikan majlis ta'lim di Kwitang, kemudian mendirikan madrasah "Unwan al-Falah". Perguruan ini adalah perguruan Islam pertama yang mengajarkan pengetahuan umum di samping ilmu-ilmu bahasa Arab.

11. Pada awal berdirinya, Pesantren As'adiyah Sengkang bernama Madrasah Arabiyah Islamiyah (MAI) Wajo. Didirikan oleh Gurutta H. Muhammad As'ad al-Bugisi pada tahun 1930 yang berawal dari pengajian halaqah di rumah beliau pada tahun 1928, tidak lama setelah ia kembali dari Mekkah al-Mukarramah.

12. Gurutta adalah istilah lokal (Bugis) yang merupakan gelar non-formal oleh masyarakat Muslim setempat kepada seseorang yang mempunyai ilmu agama yang tinggi. Guru itu sendiri berarti orang yang mengajar, sedangkan kata " $t a$ " pada "Gurutta" berfungsi sebagai "kepemilikan" yang kemudian diartikan "Guru Kita". Ada juga istilah lain untuk menyebut seorang ahli dalam ilmu agama "To Panrita" yang artinya orang berilmu.

13. Manggaji Tudang adalah sistem pengajaran yang biasa juga disebut halaqah. Mangaji berasal dari tradisi mengaji al-Qur' an yang kemudian penggunaannya diperluas dan dipakai untuk menyebut aktivitas belajar (mengaji) di luar alQur'an, seperti mengkaji hadis, kitab-kitab fikih klasik (kitab kuning), dan selainnya. Pada model pembelajaran ini, gurutta (kiai) duduk di tengah sambil membaca, menerjemah, dan menjelaskan matan kitab, sementara para santri duduk melingkar sambil mencatat penjelasan gurutta yang pada umumnya memakai bahasa Bugis.

14. Gurutta As'ad mempunyai beberapa nama yang sering dikenakan kepada beliau. Kadang-kadang masyarakat memanggilnya Gurutta Pung Aji Sade', Puang Aji Sade', atau Gurutta Sade'. Untuk keperluan penulisan, penulis memakai nama Gurutta Sade'.

15. Lihat Hamzah Mangguluang, Ana wa as-Syeikh, (Sengkang, 1989), h. 1-2. 
16. Muhammad Yunus Pasanreseng, Sejarah, Lahir dan Pertumbuhan Pondok Pesantren As'adiyah Sengkang, Pengurus Besar As'adiyah, 1989-1992.

17. Muhammad Yunus Pasanreseng, Sejarah, Lahir dan Pertumbuhan Pondok Pesantren As'adiyah Sengkang, h. 45-46.

18. Muhammad Yunus Pasanreseng, Sejarah, Lahir dan Pertumbuhan Pondok Pesantren As'adiyah Sengkang, h. 46.

19. Muhammad Yunus Pasanreseng, Sejarah, Lahir dan Pertumbuhan Pondok Pesantren As'adiyah Sengkang, h. 46-47.

20. Baca kembali Hamzah Mangguluang, Ana wa as-Syeikh h. 2-3. Lihat pula, Muhammad Yunus Pasanreseng, Sejarah, Lahir dan Pertumbuhan Pondok Pesantren As'adiyah Sengkang, h. 47.

21. Gurutta Daud Ismail, al-Ta'rif bi al-'Alim al-'Allamah, tanpa data, h. 7.

22. Aminah Adnan, Pimpinan Pondok Pesantren Putri As'adiyah, Wawancara, Sengkang, 25 Desember 2004.

23. Perubahan nama dari MAI Sengkang menjadi Madrasah As'adiyah ditempuh untuk mengingat jasa-jasa Gurutta As'ad sebagai ulama besar salah satu pelopor pembaruan pendidikan Islam Indonesia di Sulawesi Selatan. Meskipun perubahan nama tersebut terjadi satu tahun setelah wafatnya beliau, tetapi tanggal resmi Madrasah As'adiyah tetap merujuk pada tahun 1930 pada saat MAI Sengkang pertama kali didirikan oleh Gurutta As'ad.

24. Muhammad Yunus Pasanreseng, Sejarah, Lahir, dan Pertumbuhan Pondok Pesantren As'adiyah Sengkang, h. 263-267.

25. Sulaiman Abdullah, Riwayat Hidup Singkat, Sengkang: t.p., 2005, h. 1.

\section{DAFTAR PUSTAKA:}

Azra, Azyumardi, Historiografi Islam Kontemporer: Wacana, Aktualitas, dan Ator Sejarah, Jakarta: PT. Gramedia Pustaka Utama, 2002.

Mastuki dan M. Ishom el-Saha, Intelektualisme Pesantren: Potret Tokoh dan Pertumbuhan Pesantren, cetakan kedua, Jakarta: Diva Pustaka, 2004.

Suwito dan Muhbib, "Jaringan Intelektual Kyai Pesantren di Jawa-Madura Abad 20", Laporan Penelitian, Jakarta: Depag RI, 2000.

Ali, A. Mukti, "K.H. Ahmad Dahlan dalam Perspektif Kebangkitan Islam", dalam Endang Basri Ananda (ed.), 70 Tahun Prof. Dr. H.M. Rasyidi, Jakarta: Harian Pelita, 1985.

Mas'ud, Abdurrahman, Dari Haramain ke Nusantara: Jejak Intelektual Arsitek Pesantren, Jakarta: Kencana, 2006.

Mastuki HS dan M. Ishom, Intelektualisme Pesantren: Potret Tokoh dan Cakrawala Pemikiran di Era Pertumbuhan Pesantren, Jakarta: Diva Pustaka, 2003.

Hasanuddin, Muhammad Irfan, "The Pesantren As'adiyah Sengkang: A Study on Continuity and Change of Pesantren Tradition", Thesis, Jakarta: UIN Syarif Hidayatullah Jakarta, 2006, figure 2.

Indra, Hasbi, Pesantren dan Transformasi Sosial: Studi Atas Pemikiran K. H. Abdullah Syafei dalam Bidang Pendidikan Islam, Jakarta: Penamadani, 2003.

Mangguluang, Hamzah, Ana wa as-Syeikh, Sengkang, 1989. 
Pasanreseng, Muhammad Yunus, Sejarah, Lahir dan Pertumbuhan Pondok Pesantren As'adiyah Sengkang, Pengurus Besar As'adiyah, 1989-1992.

Daud Ismail, al-Ta'rifbi al-'Alim al-'Allamah, tanpa data.

Adnan, Aminah, Pimpinan Pondok Pesantren Putri As'adiyah, Wawancara, Sengkang, 25 Desember 2004.

Sulaiman Abdullah, Riwayat Hidup Singkat, Sengkang: t.p., 2005. 